\title{
Modern determination of vertical deflections using digital zenith cameras
}

\author{
Christian Hirt ${ }^{1}$, Beat Bürki ${ }^{2}$, Anna Somieski ${ }^{3}$, Günter Seeber ${ }^{4}$
}

Citation: Hirt C., Bürki, B., Somieski, A., Seeber, G. (2010) Modern Determination of vertical deflections using digital zenith cameras. Journal Surveying Engineering 136(1), Feb 2010, 1-12. DOI: 10.1061/_ASCE_SU.1943-5428.0000009.

\begin{abstract}
At the beginning of the $21^{\text {st }}$ century, a significant technological change took place in geodetic astronomy. In Zurich and Hannover, digital zenith camera systems were developed based on digital imaging sensors (CCD) that strongly improved the degree of automation, efficiency and accuracy of the observation of the direction of the plumb line and its vertical deflection. This paper describes the instrumental design of the new digital zenith camera systems and gives an overview of the data processing with focus on the models used for astrometric data reduction and tilt correction. Results of frequently repeated observations of vertical deflections and comparison measurements show an accuracy of vertical deflection measurements of better than 0.1 arc seconds. Application examples for vertical deflection data from zenith camera observations, such as the high-precision local gravity field determination in engineering projects and gravity field validation are summarized.
\end{abstract}

\section{DOI: 10.1061/_ASCE_SU.1943-5428.0000009}

\section{Introduction}

Geodetic astronomy is the only discipline that provides methods for the direct observation of the direction of the plumb line. Until the middle of the last century, exclusively astrogeodetic methods allowed the absolute determination of longitude and latitude related to the global terrestrial coordinate system. Essential early applications were navigation at sea, positioning (e.g. on expeditions), determination of Earth dimensions (historical arc measurements), orientation of geodetic networks or reference ellipsoids, determination of geoid profiles using the method of astronomical leveling and the observation of Earth orientation parameters. Meanwhile, most of the traditional astrogeodetic tasks were taken over by space geodetic techniques (e.g. GPS for global positioning, Very Long Baseline Interferometry VLBI and Satellite Laser Ranging SLR for the determination of Earth orientation).

\footnotetext{
1 Associate Professor, Department of Geomatics, HafenCity University Hamburg, Hebebrandstr. 1, 22297 Hamburg, Germany.
}

Now at: Western Australian Centre for Geodesy, Curtin University of Technology, GPO Box 1987, Perth, WA 6845, Australia.

E-mail: chris.hirt@web.de

2 Senior Scientist, Geodesy and Geodynamics Lab, Institute for Geodesy and Photogrammetry, ETH Zurich, HPV H 51, WolfgangPauli-Strasse 15, CH-8093 Zürich, Switzerland.

E-mail: buerki@geod.baug.ethz.ch

${ }^{3}$ Research Associate, Geodesy and Geodynamics Lab, Institute of Geodesy and Photogrammetry, ETH Zurich, HPV H 51, WolfgangPauli-Strasse 15, CH-8093 Zürich, Switzerland.

E-mail: anna.eve@gmx.ch

4 Professor, Institut für Erdmessung, Leibniz University of Hannover, Schneiderberg 50, 30167 Hannover, Germany.

Email: guenter@ursmaris.de
The direction of the plumb line and its vertical deflection provide valuable information on the structure of Earth's gravity field. For several decades, astrogeodetic observations were primary gravity field observables and used for astrogeodetic geoid determinations (e.g. Helmert 1913 in the Harz mountains, Northern Germany, Bomford in Europe 1971). Observations were performed visually; therefore requiring not only dedicated instruments (e.g. DKM3A, T4, Astrolabes) but also well-trained and skilled observers.

Major improvements of astrogeodetic observation techniques could be achieved since the 1970's when transportable photographic zenith cameras were successfully designed and constructed at the University of Hannover (cf. Gessler 1975, Wissel 1982) and ETH Zurich (Bürki 1989). Similar developments took place in Italy (Birardi 1976) and Austria (Chesi 1984). Thanks to a fully automated registration of exposure epochs and level readings, this new instrumental type overcame the problem of personally influenced results (personal equation effects) to a large extent. Moreover, the zenith cameras allowed a significantly accelerated and simplified observation procedure. Such automated instruments were extensively applied in numerous European and American countries (e.g. Switzerland, Austria, Germany, Denmark, Greece, Canada, Brazil, Venezuela) for local and regional geoid determination and geophysical applications up to the nineties of the $20^{\text {th }}$ century (e.g. Seeber and Torge 1985).

Compared with current geodetic standards, the main drawback of the analogue photographic technique was the acquisition of star coordinates from the photographs which was performed manually or semi-automated using a comparator. The processing of a single station usually lasted 3-5 hours, thus requiring man-power and keeping the costs of astrogeodetic measurements at a relatively high level. In addition, due to the increasing number of available gravity observations and satellite data, gravimetric computation 
techniques advanced with the result that more gravity field models based on gravimetric techniques became available (e.g. Torge 2001). As a consequence, the significance of astrogeodetic methods for the determination of the Earth gravity field decreased considerably in the 1990's.

The invention of extremely light-sensitive digital imaging sensors (charge-coupled device, CCD) which are able to replace the analogue photographic techniques has revolutionized observational astronomy in general and astrometry in particular (e.g. Buil 1991, Howell 2000). Also the field of geodetic astronomy did not remain unaffected by these developments. CCD sensors used for digital imaging of stars basically provide the image data directly after observation which is indispensable for online-processing. This way the conceptual disadvantage of photographic observations - the chemical development of the photos and the need for manual evaluation by means of a comparator could be completely overcome so that the efficiency of astrogeodetic methods increases significantly. First developments at the beginning of the digital era were published in the field of direction measurements to artificial satellites more than one decade ago (Schildknecht 1994). In consequence of this new technique, concepts for the automated observation of the plumb line were presented by research groups in Munich (cf. Eissfeller and Hein 1994) and Vienna (e.g. Bretterbauer 1997). First instrumental approaches were published, e.g. by Fosu (1999), however, without progressing to field-capability yet. This requires robust implementation of hardware and electronic components, the development of suited data acquisition and processing software, proper calibration procedures and analysis of the measuring accuracy.

At the Institut für Erdmessung (IfE), University of Hannover and the Geodesy and Geodynamics Laboratory (GGL), ETH Zurich, intensive research in astrogeodetic use of CCD technology was started at the beginning of the $21^{\text {st }}$ century. The existing photographic zenith cameras TZK2 and TZK3 were re-designed and equipped with CCD imaging sensors to Digital Zenith Camera Systems (DZCS). The Hannover digital zenith camera is called TZK2-D (Transportable Zenitkamera 2 - Digitalsystem), whereas the DZCS implemented at ETH Zurich is named DIADEM (Digital Astronomical Deflection Measuring System). The results already obtained in the development phase have been encouraging as they clearly indicated the potential of automated astrogeodetic instrumentations for local gravity field studies (Hirt 2001, Hirt and Bürki 2002). In 2003, hardware and software details of both DZCSs were completed and full field-capability was achieved for the first time. The performance of this new generation of astrogeodetic instruments for the determination of vertical deflections could be successfully demonstrated during a first common field campaign which took place in Switzerland in 2003 (Müller et al. 2004, Hirt 2004). In the sequel, both systems have been further improved in terms of automation and accuracy (e.g. Hirt and Seeber 2006, 2008, Somieski 2008) and were extensively used for local and regional gravity field determinations in Switzerland, Greece, Portugal, Northern Germany, Bavaria and the Netherlands at several 100 new field stations. In recent time, developments of similar astrogeodetic instrumentations have been started at other universities (Kudrys 2007).
The present paper focuses on the highly-precise determination of astrogeodetic vertical deflections using digital zenith cameras. A description of alternative astrogeodetic instrumentation, a CCD-theodolite that can be used for the determination of vertical deflections and astronomical azimuths, is given by Guillaume and Bürki (2008). Besides the astronomical observation of vertical deflections, there exist several other techniques capable of determining vertical deflections. The combination of GNSS (global navigation satellite system) measurements and spirit leveling in local geodetic networks yields vertical deflection data independent of star observations (e.g. Soler et al. 1989, Tse and Iz 2006). Gravity measurements are commonly used for the computation of gravimetric vertical deflections applying the Vening-Meinesz formula (e.g. Torge 2001, p. 283). Vertical deflections can also be derived from highdegree spherical harmonic models (e.g. EGM08, EGM96) where the accuracy depends on the available spherical degree (Jekeli 1999). In local geodetic networks, vertical deflections can be determined from a combination of GNSS observations and local terrestrial measurements (distances, horizontal and vertical angles) using the Procrustes Algorithm (Grafarend and Awange, 2000). Differences of vertical deflections are provided by e.g. reciprocal simultaneous zenith angle observations (Torge 2001, p. 299). Another approach is to use GPS/INS (Global Positioning System/Inertial Navigation System) vector gravimetry measurements (cf. Li and Jekeli 2008) for the determination of vertical deflections. For a review of further techniques capable of providing vertical deflections the reader is referred to Wolf (1981).

\section{Observation Principle}

The simple astrogeodetic observation principle realized with DZCS remained - in essence - unchanged throughout the decades: The direction of the plumb line $(\Phi, \Lambda)$ is obtained by means of direction measurements to celestial objects, primarily stars, whose equatorial coordinates right ascension $\alpha$ and declination $\delta$ are given in the International Celestial Reference System ICRS.

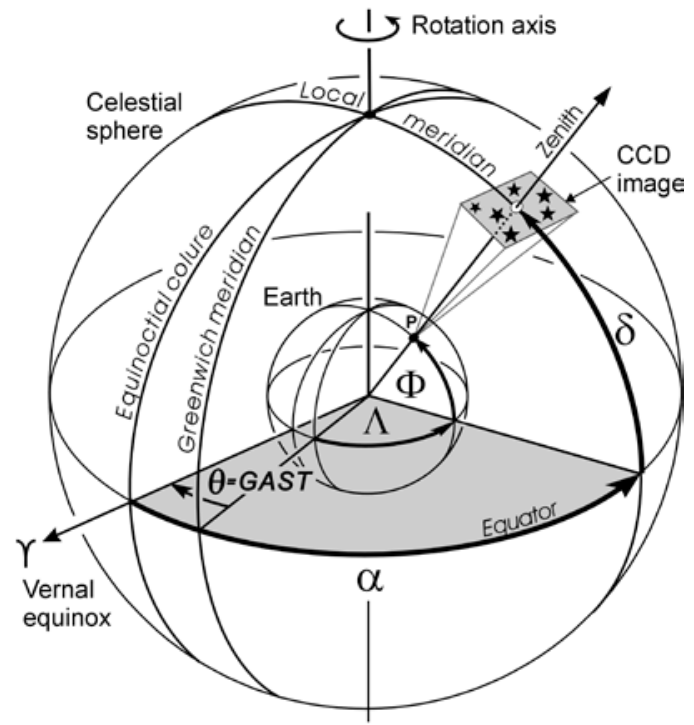

Figure 1. Basic principle of the direct determination of the plumb line's direction $\Phi, \Lambda$ 
The astronomical coordinates longitude $\Lambda$ and latitude $\Phi$ define the spatial direction of the plumb line with respect to the International Terrestrial Reference System ITRS (Fig. 1). ITRS and ICRS are linked by Greenwich Sidereal Time GAST being a measure for Earth's rotation phase angle. Astrogeodetic methods use the equivalence of astronomical coordinates (plumb line $\Phi, \Lambda$ ) and equatorial coordinates (zenith direction $\alpha, \delta$ ) for a star exactly located in zenith:

$$
\Phi=\delta \quad \Lambda=\alpha-\text { GAST }
$$

Since a corresponding star is usually not exactly transiting through zenith, a digital zenith camera is used for imaging the star field surrounding the zenith on a CCD for interpolation. Vertical deflections $(\xi, \eta)$ are directly obtained by calculating the difference between the local plumb line and the camera's geodetic coordinates $(\varphi, \lambda)$ to be determined with GPS (Fig. 2). In linear approximation, the components $(\xi, \eta)$ are usually computed as (cf. Torge 2003, p. 220, Heiskanen and Moritz 1967, p. 186):

$$
\xi=\Phi-\varphi \quad \eta=(\Lambda-\lambda) \cos \varphi .
$$

In the literature, $(\xi, \eta)$ are also known as surface vertical deflections or Helmert vertical deflections. It should be noted that second order terms of vertical deflections (cf. Jekeli 1999), which are neglected in Eq. 2, must be taken into account in mountainous areas for highest accuracy requirements. Vertical deflections $(\xi, \eta)$ play an important role in geoid determination, e.g. in the concept of astronomical leveling, as they represent the inclination of the geoid with respect to the ellipsoid (e.g. Torge 2001). Vertical deflections are also required to reduce terrestrial survey data to the ellipsoid (e.g. Featherstone 1997).

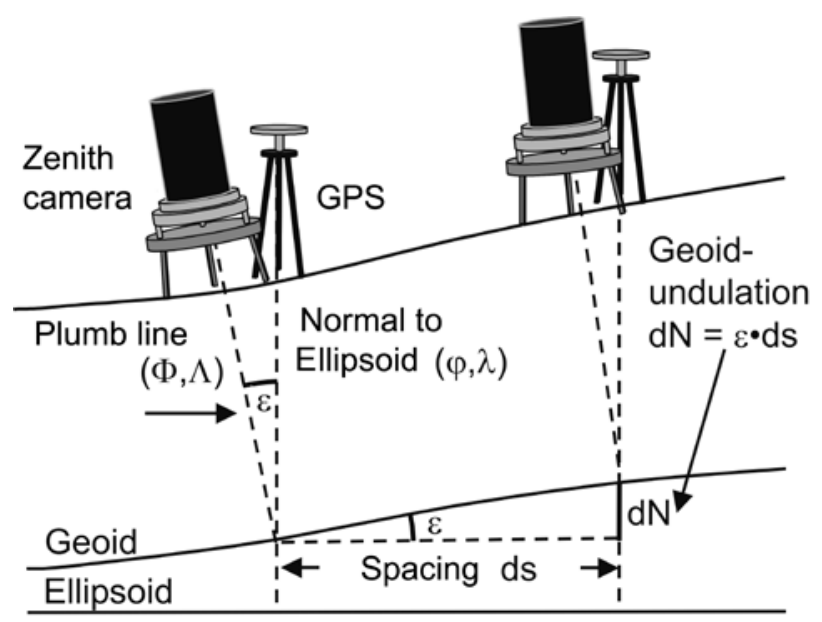

Figure 2. Basic principle of determination of vertical deflections $(\xi, \eta)$ measurements by combining zenith camera and GPS in the context of astronomical leveling

\section{Instrumental design of the digital zenith camera}

The instrumental designs of the Hannover zenith camera TZK2-D (Hirt 2004) and of the Zurich zenith camera DIADEM (Bürki et al. 2004, 2007b) are quite similar. Both instruments basically consists of an objective directed to the zenith, a CCD-sensor used for star imaging, a GPS receiver deployed for the observation of geodetic coordinates as well as time tagging, and a pair of high-precision tilt sensors (cf. Fig. 3). The cameras employ dedicated mechanics: a motorized superstructure, consisting of lens, CCD and tilt sensors, forms the upper part of the system and can be rotated by $180^{\circ}$ in azimuth, thus allowing to observe in two opposite camera directions. A precision ball bearing separates the superstructure from the substructure that is connected to a robust, motorized tripod (a stable base plate with three electric actuators) which enables automatic leveling. An integrated field computer applied for device and data flow control, data storage and on-line data processing completes the astrogeodetic measuring system. The power supply is realized with several $12 \mathrm{~V}$ accumulators enabling operation of the system under field conditions. The technical

\begin{tabular}{|c|c|c|}
\hline DZCS & TZK2-D & DIADEM \\
\hline Developer & $\begin{array}{l}\text { Univ. } \\
\text { Hanover }\end{array}$ & ETH Zurich \\
\hline CCD & $\begin{array}{ll}\text { Kodak } & \text { KAF } \\
1602 \mathrm{E} & \end{array}$ & KAF 3603 E \\
\hline Array size & 1530 x 1020 px & 3072 x 2048 px \\
\hline Pixel size & \multicolumn{2}{|l|}{$9 \mu \mathrm{m} \times 9 \mu \mathrm{m}$} \\
\hline Pixel scale & \multicolumn{2}{|l|}{1.86 arc sec /px } \\
\hline FOV & $\begin{array}{l}47.2^{\prime} \times 31.5^{\prime}(= \\
\left.0.42 \operatorname{deg}^{2}\right)\end{array}$ & $\begin{array}{l}95,2^{\prime} \text { x 53.5' } \\
\left(=1.68 \mathrm{deg}^{2}\right)\end{array}$ \\
\hline $\begin{array}{l}\text { Exposure } \\
\text { time }\end{array}$ & \multicolumn{2}{|l|}{$0.2-0.5 \mathrm{~s}$} \\
\hline GPS & Z12, Ashtech & $\begin{array}{l}\text { p.-blox Antaris, } \\
\text { Leica }\end{array}$ \\
\hline Tiltmeter & $\begin{array}{l}\text { HRTM, } \\
\text { Lippmann }\end{array}$ & $\begin{array}{l}\text { Wyler, } \\
\text { Zerotronic/ } \\
\text { HRTM, } \\
\text { Lippmann }\end{array}$ \\
\hline $\begin{array}{l}\text { Measuring } \\
\text { range }\end{array}$ & $\pm 600 “$ & $\pm 1^{\circ} / \pm 300^{\prime}$ \\
\hline $\begin{array}{l}\text { Accuracy } \\
\text { (absolute) }\end{array}$ & 0.04-0.05“ & $0.05-0.10^{“}$ \\
\hline
\end{tabular}
specifications of both systems are given in Tab. 1 .

Tab. 1. Technical specifications of the zenith camera systems TZK2-D and DIADEM 


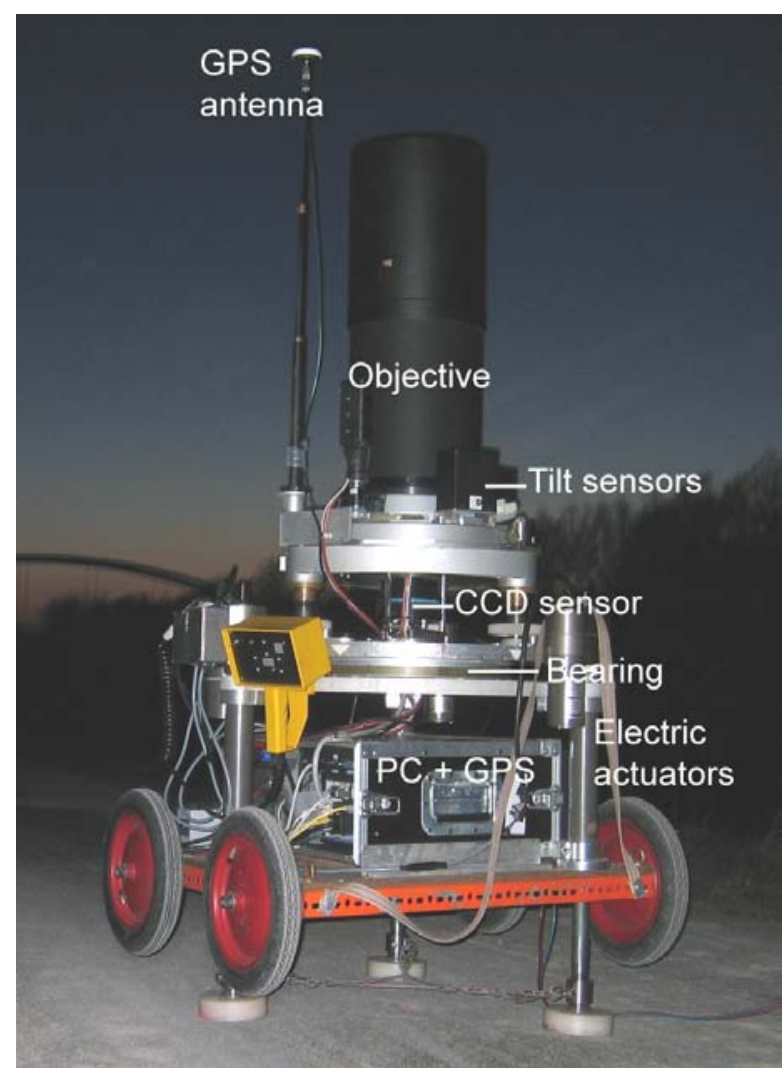

Figure 3. TZK2-D during operation

The objective (type Zeiss Mirotar, similar to MaksutovCassegrain, a lens-mirror combination) has an aperture of $200 \mathrm{~cm}$ and achieves a focal length of $102 \mathrm{~cm}$ along with a compact architecture (about $40 \mathrm{~cm}$ overall length). A main benefit of this objective is the excellent imaging quality practically free of radial distortion (cf. Hirt 2004). A disadvantage is the temperature dependency of the location of the focal plane (gradient of about $0.03 \mathrm{~mm} \mathrm{~K}^{-1}$ due to the metal used for the tube). A motorized focusing unit that automatically changes the vertical position of the CCD, based on temperature measurement, is used for compensation. Thereby unfocused star images are avoided that may reduce the observational accuracy.

The CCD imaging sensor (Kodak KAF, full frame transfer, cf. Fig. 4, left) applied for star imaging has an array size of 1.5 million pixel (TZK2-D) and 6 million pixel (DIADEM), respectively, while the pixel size is identical for both cameras ( $9 \mu \mathrm{m}$ which corresponds to an angular scale of 1.86" per pixel). The field of view (FOV) of the digital zenith cameras is about $0.42 \mathrm{deg}^{2}$ (TZK2-D) and $1.68 \mathrm{deg}^{2}$ (DIADEM), respectively. In most cases, a sufficient star count (at least 10 or more stars) is obtained using the 1.5 million pixel CCD. However, the larger sensor used by DIADEM has some advantages, e.g. in the case when thin clouds appear in zenith. Unlike most other telescopes used for astrometry, the digital zenith camera is a non-tracking instrument and requires a very stable set up during operation. Due to the optical specifications, a limiting magnitude of about 13-14 magnitude is obtained after short exposure times of $0.2-0.5 \mathrm{~s}$ (this corresponds to a total star count of about 10 million stars available on the sphere). A further extension of exposure time is not suitable because the imaged stars start to form trails instead of circles due to the influence of Earth rotation.
An electromechanical shutter with 5 blades (type Melles Griot UTS203) is used for steering the exposure of the CCD. In order to time-tag the epoch of exposure, the control unit of the shutter is linked to the GPS-receiver synchronized to the GPS time scale. At the beginning of each zenith camera exposure, a logical signal (TTL pulse) is directed simultaneously from the CCD control unit to the shutter and to the GPS-receiver, so that the exposure epoch is marked on GPS time scale. GPS time is rigorously connected to UTC, UT1, GMST and finally GAST, required in Eq. 1. For details on these time scales and their conversions, the reader is referred to e.g. Seidelmann (1992) and Seeber (2003). In order to eliminate systematic errors of the time-tagging procedure, a calibrated shutter motion function is applied.
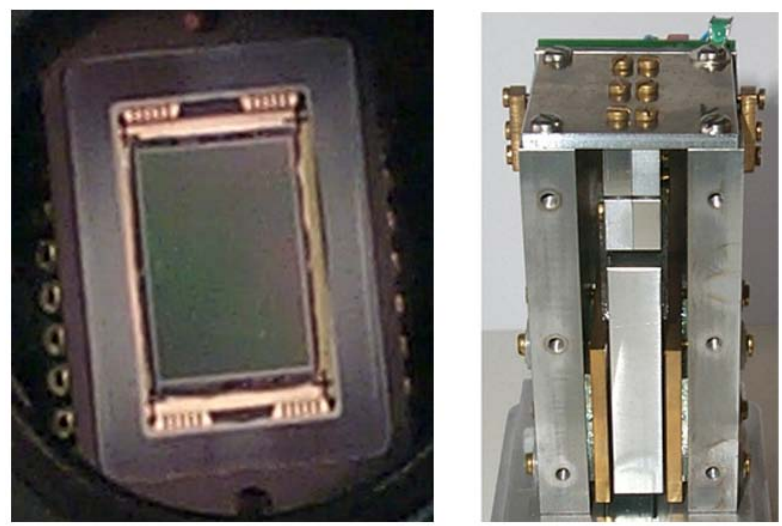

Figure 4. Left: CCD sensor KAF1602E (1530 x1020 pixel, corresponding to $1.4 \mathrm{~cm} \times 0.9 \mathrm{~cm}$ array size). Right: HRTM pendulum tilt sensor ( $8 \mathrm{~cm}$ height)

Tilt measurements are of utmost importance for vertical deflection measurements for refering the camera's optical axis to the plumb line. In the past, tilt measurements incorporated one of the limiting parts of (photographic) zenith cameras. Along with the development of the DCZS, efforts were made in order to overcome these limitations. Recently constructed tilt sensors type HRTM (highresolution tilt meter by Lippmann company for Geophysical Instruments, Germany) have been investigated and adapted to the requirements associated with zenith camera measurements (e.g. high accuracy, no or small zero offset variations, short settling times). The HRTM (Fig 4, right) is an electronic pendulum inclination sensor (constructed as three-plate-condenser) whose voltage signals are digitized with a scan frequency of $100 \mathrm{~Hz}$ using a data acquisition card. Two HRTM sensors installed in perpendicular orientation are deployed in fixed connection with the objective and CCD on the superstructure. They are used for alignment of the camera to zenith before observation. A second task is to monitor small, but inevitable deviations between instrument and plumb line occurring and varying during observation. The tilt corrections computed from the tilt signals (acquired in two camera directions) are accurate to about 0.04-0.05” (Hirt and Kahlmann 2004, Hirt 2004). In order to attain this accuracy level, low-pass signal filtering, rigorous elimination of the zero offsets, the use of appropriate transformation models as well as precise calibration of the scale factors is required 


\section{Field routine}

All components of the DZCS are either installed onto a small trolley (Fig. 3) transported to the field stations in a van, or integrated into a hanger (Fig. 5). Above the observation site (e.g. streets), the electric actuators of the measuring system are extended with the result that the tripod legs (connected to the actuators) are placed on the ground and the DCZS is lifted up into a stable position. Prior to the observation, sophisticated and automated procedures are carried out for instrumental set-up. A fully automated leveling of the zenith camera is accomplished by means of the motorized tripod. The readings of the tilt sensors are converted into electric pulses and are being sent to the actuators, changing the effective length of the tripod legs. The leveling procedure is repeated until the misalignment between camera axis and plumb line is below 2". The focusing of star images is performed using the focus unit that moves the CCD sensor vertically into the focal plane of the objective. These computer-controlled preparation steps usually take a few minutes.

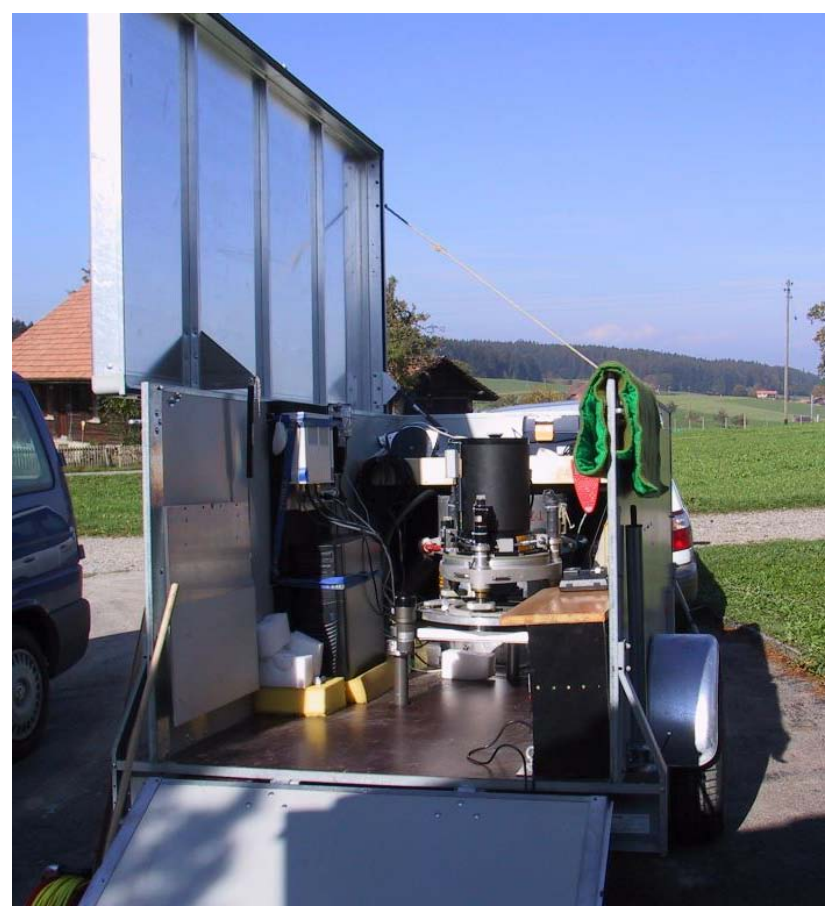

Figure 5. DIADEM mounted in a hanger for transport between stations

The automated data acquisition procedure comprises digital star imaging, GPS-based time-tagging and digitization of the tilt signals. The procedure starts by opening the shutter of the CCD in order to image the star field located in zenith. The shutter opening signal is used for marking the exposure epoch by means of the GPS-receiver as well as for synchronizing the tilt measurements. At the end of the exposure, the complete data set is transferred and stored by the steering computer. Then a motorized rotation of the superstructure changes the camera orientation by $180^{\circ}$ in azimuth and the data acquisition procedure is repeated in the second camera position.
Two images, taken in opposite camera directions, form a single observation together with the corresponding epochs and tilt values. In most cases, 20 to 50 stars (TZK2-D) and 80 to 200 stars (DIADEM), respectively, are contained in a single image. These numbers are exceeded when the galactic plane (Milky Way) is transiting zenith (e.g. in autumn or winter in Central Europe). Just in rare cases the star count falls short of 10 stars (DIADEM: 40 stars), e.g. when sky regions near the galactic poles are up. Basically, a single solution (taking about 25 - 30 s observation time) already allows the computation of the vertical deflection. In order to enhance the observational accuracy and redundancy, usually a sequence of 40 - 50 single observations is acquired at a single station, called field observation. Such a measurement requires a total of about $20-25$ min, including set-up time. Vertical deflections from DZCS observations therefore usually are based on the evaluation of directions to some thousand stars at each field station.

The observation is carried out in two camera directions (I and II) in order to reduce the impact of the zero offsets of the CCD and the tilt sensors. As a refined observation technique, the data acquisition is generally performed in directions I-IIII-I. Such a symmetric sequence also eliminates linear variations of the sensor offsets which may occur due to temperature changes during observation. If the tilt of the camera exceeds a user-defined threshold (e.g. 10") before the beginning of each single observation, the above described leveling procedure immediately re-aligns the camera axis to the plumb line. Thereby small tilt readings are guaranteed (even at those observation sites where the instrument tends to sink, e.g. on frozen soil). As a consequence, the impact of uncertainties of the tilt sensor's scale factors on the observational results is reduced.

The geodetic coordinates $(\varphi, \lambda)$ of the station are determined before or during the astrogeodetic observation with GPS in differential mode, using carrier phase measurements. The use of national satellite positioning services (e.g. SAPOS in Germany, SWIPOS in Switzerland or CORS in the United States) provides the geodetic position of the camera accurate to some centimeters (corresponding to an angular accuracy of about 1 milli arc second, mas), thus being a less critical part related to vertical deflection measurements with modern DZCS.

\section{Data processing}

A software package called AURIGA (Automatic Real-time Image Processing System for Geodetic Astronomy) has been developed for the processing of DZCS measurements (Hirt 2001, Hirt und Bürki 2002, Hirt 2004). This software system realizes a completely automated data processing chain. The software extracts stars from the image data, accesses star catalogue data, performs a precise astrometric data reduction and computes required corrections (tilt, polar motion), eventually yielding astronomical coordinates $(\Phi, \Lambda)$ of the camera and the vertical deflection $(\xi, \eta)$ by taking the geodetic position into account (Fig. 6). The AURIGA data processing usually takes some seconds per single solution, thus enabling real-time determination of vertical deflection data. In the following, a summary of the data processing is given with focus on the functional models applied. 


\section{Image coordinates}

Digital astrometric image data implicitly contain information on directions (angles) to stars near zenith. Star images are characterized as adjacent pixel regions with a minimum diameter (2-3 pixel), almost circular in shape and significantly brighter than the surrounding pixel of the night sky. Pixel regions of imaged stars are extracted from the image using segmentation methods, e.g. the region growing technique (cf. Haralick and Shapiro 1992). The basic idea of this method is a systematic search over the complete image for pixel exceeding a minimum brightness (gray value) and to associate all other adjacent pixel with a similar brightness, thus representing a segment (Fig. 7 A-C).

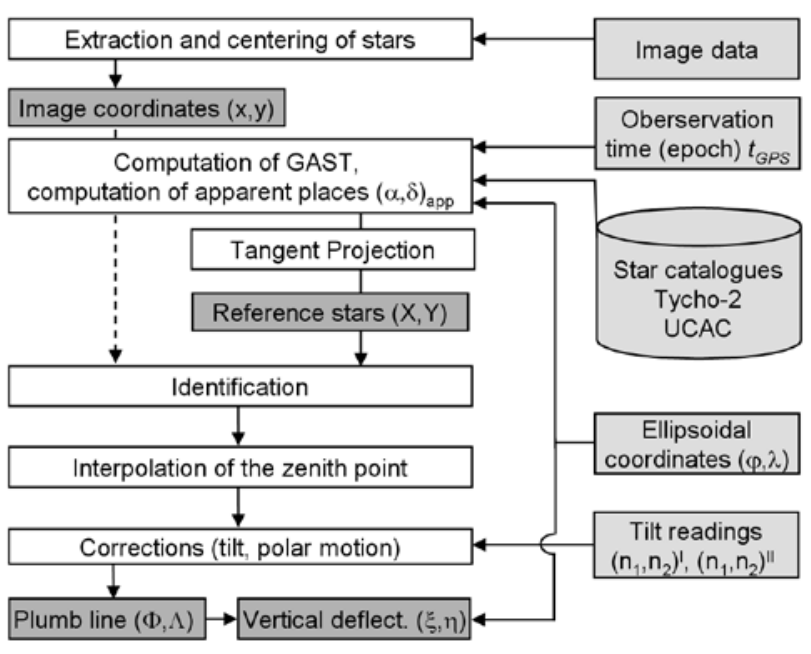

Figure 6. Simplified scheme of the data processing

Once all adjacent and bright pixel regions are extracted, the image coordinates $(x, y)$ of the segments are computed as image moments, in that, all image coordinates $(x, y)_{\mathrm{i}}$ of each segment (consisting of pixel $i=1 \ldots n$ ) are linearly weighted with the corresponding gray value $g_{\mathrm{i}}$ :

$$
x=\frac{1}{\sum g_{i}} \sum x_{i} \cdot g_{i} \quad y=\frac{1}{\sum g_{i}} \sum y_{i} \cdot g_{i}
$$

A second approach applicable for the determination of image coordinates $(x, y)$ in AURIGA is based on the concept of adapting a model function (point spread function) to the star image, using a least squares adjustment (Fig. 7 D). The Gaussian error distribution curve is applied as a standard model which describes the intensity distribution of the star image in good approximation (e.g. Stone 1988, Monet and Dahn 1983, Winter 1999):

$\varphi(x, y, a, b, r)=a \exp \left(-\ln 2 \frac{\left(x_{i}-x\right)^{2}+\left(y_{i}-y\right)^{2}}{r^{2}}\right)+b-g_{i} \longrightarrow \min$

with the unknown parameters $a$ amplitude, $b$ offset (average brightness of the background), $r$ radius of star image, $x, y$ center of star image and the observations $(x, y)_{\mathrm{i}}$ coordinates of star pixel, $g_{i}$ gray values of star pixel. Both methods for the measurement of image coordinates yield accuracies mostly between 0.1-0.2 pixel (corresponding to an angular precision of 0.3 "- 0.4 ") per star, whereby the point spread function performs somewhat better than the image moment method.
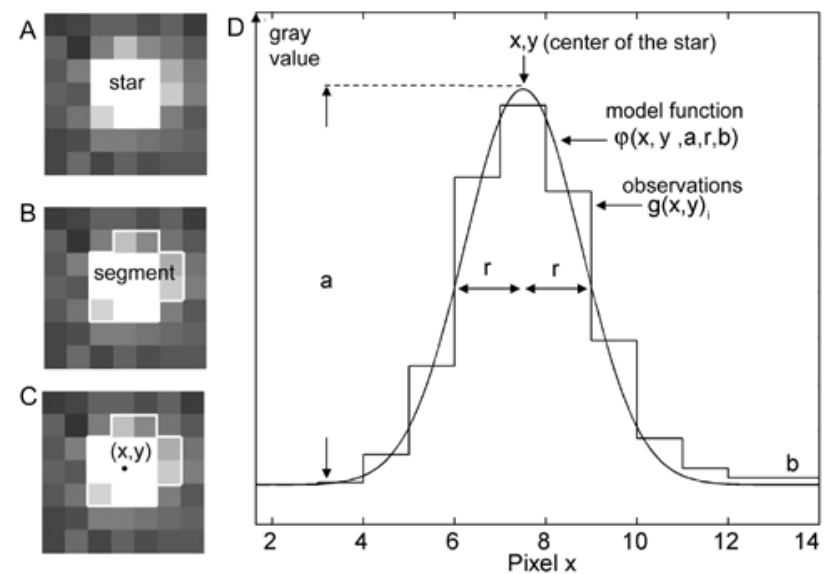

Figure 7. Segmentation of star images and centering. A: star image. B: segmentation using region growing. C: Determination of image coordinates using the moment method. D: Determination of image coordinates by fitting a point spread function to the gray values of the star.

\section{Star catalogues}

Star catalogues contain the equatorial coordinates declination $\delta$ and right ascension $\alpha$. They incorporate the celestial reference system (ICRS) for astrogeodetic observations and are necessary for reducing the astrometric image data. Based on the successful Hipparcos astrometry space mission in 1993, the Hipparcos star catalogue with unprecedented positional accuracies of 1 mas for about 120,000 stars have been published (ESA 1997). In the following, the catalogues Tycho-2 (Hog et al. 2000) and UCAC (Zacharias et al. 2004) were compiled as densifications of the Hipparcos catalogue and the ICRS, respectively, in the optical domain. Tycho-2 and UCAC are well-suited catalogues for the processing of DZCS observations as they provide reference positions for a couple of million stars $\left(14^{\text {th }}\right.$ magnitude and even fainter) at an (external) accuracy level of 0.02"-0.10" (cf. Zacharias et al. 2000).

In order to retrieve appropriate reference stars from the Tycho-2 or UCAC star catalogue data base, the geodetic position of the camera $(\varphi, \lambda)$, as observed by GPS, is introduced as approximate astronomical coordinates $(\Phi, \Lambda)_{0}$. A conversion of $(\Phi, \Lambda)_{0}$ with GAST yields approximate equatorial coordinates $(\alpha, \delta)_{0}$ for the zenith, which is the center of the selection zone:

$\delta_{0}=\Phi_{0}, \quad \alpha_{0}=\Lambda_{0}-$ GAST.

The boundaries of the selection zone $(\alpha, \delta)_{\min },(\alpha, \delta)_{\max }$ are obtained by considering the size of the FOV of the camera and small tolerances, accounting for the uncertainties of approximation as well as for a rotated FOV (due to the random orientation of the CCD). The positions $(\alpha, \delta)$ taken from the star catalogue data base are mean star positions, referring to Epoch J2000. For astrogeodetic use, the mean 
positions are converted to apparent star positions, by taking time-dependent effects (proper motion of the stars, precession, nutation, daily and annual aberration) into account. The effect of annual parallax is neglected because for most the reference stars used in the data processing (magnitude typically between 10 and 13) parallaxes are below 0.01 " or even unavailable (cf. Hog et al. 2000). The computation of apparent star positions is comprehensively described e.g. by Kaplan et al. (1989), Seidelmann (1992) and Jekeli (2006). In AURIGA, the NOVAS-C (U.S. Naval Observatory Vector Astronometry Subroutines, cf. Bangert and Kaplan 1998) are utilized for the calculation of apparent places. According to Kaplan et al. (1989), the accuracy of this algorithm is about 1 mas (micro arc second). A comprehensive validation of the NOVAS-computations was performed by means of a comparison with other implementations (e.g. SLALIB, cf. Wallace 1994), showing a completely sufficient agreement of 1-2 mas (Hirt et al. 2005).

\section{Astrometric data reduction}

Equatorial coordinates $(\alpha, \delta)$ of the reference stars are defined on the sphere whereas image coordinates $(x, y)$ are referred to the plane coordinate system realized by the CCD-sensor. The link between both coordinate systems is usually established by plane tangent coordinates $(X, Y)$, which are also known as standard coordinates in astrometry. They are derived by a gnomonic projection of spherical coordinates $(\alpha, \delta)$ into a tangent plane (Fig. 8) that touches the sphere at the approximate zenith $(\alpha, \delta)_{0}$, as computed with Eq. 5 . The forward transformation is given by Seeber (1972):

$$
\begin{aligned}
& \cot q=\cot \delta \cos \left(\alpha-\alpha_{0}\right), \\
& X=\frac{\tan \left(\alpha-\alpha_{0}\right) \cos q}{\cos \left(q-\delta_{0}\right)}, \\
& Y=\tan \left(q-\delta_{0}\right) .
\end{aligned}
$$

where $q$ is an auxiliary quantity. The equation of the backward equation reads (Gessler 1975):

$$
\begin{aligned}
& \alpha=\alpha_{0}+\arctan \frac{X}{\cos \delta_{0}-\eta \sin \delta_{0}}, \\
& \delta=\frac{\arctan \left(Y+\tan \delta_{0}\right) \cos \left(\alpha-\alpha_{0}\right)}{1-Y \tan \delta_{0}} .
\end{aligned}
$$

Before setting up the functional model between the imaged stars $(x, y)$ and the tangent coordinates $(X, Y)$ of the catalogue positions, a star identification is performed. The approach used for star identification in AURIGA is based on the fact that both star fields (from the image and the catalogue) feature similar star patterns, particularly triangle configurations. Identical stars in both fields form triangles with identical aspect ratios which is a suitable criterion for matching. A detailed description of the approach is provided by Groth (1986), Valdes et al. (1995) and Hirt (2004). The process of star identification creates a definite relation between imaged stars and their match from the catalogue base, and deletes all other stars without match (e.g. faint catalogue stars not imaged on the CCD).
A simple Helmert transformation (plane 4 parameter transformation) has been found to be adequate for the precise conversion of tangent coordinates $(X, Y)$ to image coordinates $(x, y)$ of the identical stars:

$$
X=a_{1}+b_{1} x-c_{1} y, \quad Y=a_{2}+c_{1} x+b_{1} y .
$$

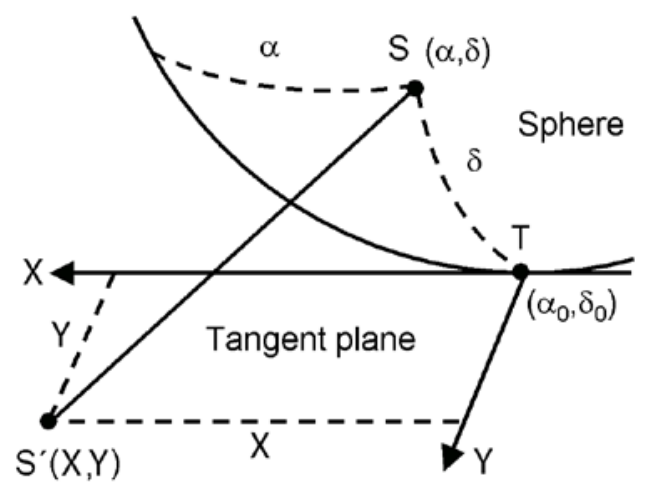

Figure 8. Principle of the tangent projection. S star, S' projected star, $\mathrm{T}$ touching point of the tangent plane.

The parameters $a_{1}, a_{2}$ are the translations between both coordinate systems and the terms $b_{1}, c_{1}$ may be used for the computation of the scale factor $m$ (about 1.86” per pixel) and the rotation angle $A$, representing the astronomical azimuth of the CCD (cf. Fig. 9):

$$
m=\sqrt{b_{1}^{2}+c_{1}^{2}} \quad,
$$

$A=\arctan \left(\frac{c_{1}}{b_{1}}\right)$

Other parameterizations, like the 6-parameter affine transformation (2 translations, 2 scale factors, a shearing and a rotation) as well as the 8-parameter projective transformation (additionally accounting for a tilt between image and tangent plane) have been tested, however without further reducing the residuals of the Helmert transformation. This result is in agreement with the fact that CCD-sensors used for imaging in astronomy are very precisely manufactured in terms of geometry, without affine characteristics (cf. Winter 1999).

The required interpolation of the zenith point is performed separately for both images taken in camera direction I and II: Initial image coordinates $(x, y)=(0,0)$, assuming the location of the zenith in the center of the CCD, are converted into tangent coordinates (Eq. 8) and equatorial coordinates (Eq. $7)$. Using Eq. 1, approximate astronomical coordinates $(\Phi, \Lambda)$ are obtained. The average of the astronomical coordinates computed from image I and II gives a better solution due to the symmetry of observation:

$$
\Phi=\frac{\Phi^{\mathrm{I}}+\Phi^{\mathrm{II}}}{2}, \quad \Lambda=\frac{\Lambda^{\mathrm{I}}+\Lambda^{\mathrm{II}}}{2}
$$


A forward transformation of $(\Phi, \Lambda)$ into $(x, y)$ is then carried out separately for both directions I and II, using Eq. 5, Eq. 6 and inverted Eq. 8. The average values

$$
x=\frac{x^{\mathrm{I}}+x^{\mathrm{II}}}{2}, \quad y=\frac{y^{\mathrm{I}}+y^{\mathrm{II}}}{2},
$$

representing the zero offset error of the CCD, give improved image coordinates for the zenith. The described procedure is repeated and converges quickly after 2-3 iterations. As result of the iteration process, astronomical coordinates $(\Phi, \Lambda)_{R}$, defining the camera axis in the ITRS, are obtained. The attained interpolation accuracy (1 sigma) was found to be about 0.15 "- 0.2 " when 10 to 20 stars are used. Additional stars, however, do not further improve the accuracy.

\section{Corrections}

The coordinates of the cameras rotational axis $(\Phi, \Lambda)_{\mathrm{R}}$ differ from the true vertical $(\Phi, \Lambda)$ (the zenith direction) due to (1) a small misalignment which is monitored by the tilt sensors HRTM1 and 2 during observation and (2) the polar motion of the Earth. The tilt values $\left(n_{1}, n_{2}\right)^{\mathrm{I}}$ and $\left(n_{1}, n_{2}\right)^{\mathrm{II}}$ observed in camera directions I and II are used for a precise correction applying a new transformation model (Hirt 2004, 2008). This model rigorously accounts for deviations from the perpendicular orientation of the two tilt sensor axes (shearing parameter $\varepsilon$, e.g. $89.5^{\circ}$ instead of $90^{\circ}$ ) as well as for a misalignment between camera directions I and II (e.g. $179.5^{\circ}$ instead of $180^{\circ}$ ). In a first step, a shearing correction is applied separately for both directions:

$$
\begin{aligned}
& n_{1^{*}}^{I}=n_{1}^{I}, \\
& n_{2^{*}}^{I}=\frac{n_{2}^{I}}{\sin \varepsilon}-\frac{n_{1}^{I}}{\tan \varepsilon}
\end{aligned}
$$

with $\left(n_{1}, n_{2}\right)^{\mathrm{I}}$ tilt values as observed in direction I (referred to the sheared sensor axis) and $\left(n_{\left.1^{*}, n_{2 *}\right)^{\mathrm{I}}}\right.$ tilt values referred to an orthogonal coordinate system (see also Fig. 9). Analogously for the second camera direction, orthogonal tilt values $\left(n_{1^{*}}, n_{2^{*}}\right)$ are computed from the observed tilt values $\left(n_{1}, n_{2}\right)^{\mathrm{II}}$ with Eq. 13 . The required shearing parameter $\varepsilon$ is provided by a calibration. In a second step, the tilt of the camera axis $\left(n_{1}, n_{2}\right)$ is computed as function of the orthogonal

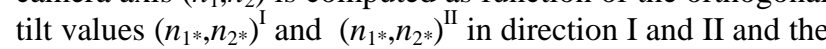
rotation angle $\mathrm{d} \alpha$ between direction I and II, being the difference between the astronomical azimuths of images $A^{\mathrm{I}}$ and $A^{\mathrm{II}}$ (Hirt 2008):

$$
\begin{aligned}
& \mathrm{d} A=A^{\mathrm{II}}-A^{\mathrm{I}}, \\
& n_{1}=\frac{(\cos d A-1)\left(n_{1^{*}}^{I I}-n_{1^{*}}^{I}\right)-(\sin d A)\left(n_{2^{*}}^{I I}-n_{2^{*}}^{I}\right)}{2(1-\cos d A)} \\
& n_{2}=\frac{(\cos d A-1)\left(n_{2^{*}}^{I I}-n_{2^{*}}^{I}\right)-(\sin d A)\left(n_{1^{*}}^{I I}-n_{1^{*}}^{I}\right)}{2(1-\cos d A)} .
\end{aligned}
$$

This model fully accounts for a misalignment between both camera directions and eliminates arbitrary zero offset errors of the tilt sensors from the results. The computed tilt values $\left(n_{1}, n_{2}\right)$ refer to the orthogonal tilt coordinate system in camera direction I and represent the tilt of the camera axis with respect to the plumb line. Tilt corrections $\left(\delta \Phi_{n}, \delta \Phi_{n}\right)$ are computed by rotating the values $\left(n_{1}, n_{2}\right)$ to the local astronomical coordinate system (Fig. 9) and by accounting for the convergence of the meridians in longitudinal direction (Hirt 2004):

$\delta \Phi_{\mathrm{n}}=\cos \left(\alpha^{I}+\beta\right) n_{1}-\sin \left(\alpha^{I}+\beta\right) n_{2}$,

$\left.\delta \Lambda_{\mathrm{n}}=\sin \left(\alpha^{I}+\beta\right) n_{1}+\cos \left(\alpha^{I}+\beta\right) n_{2}\right) / \cos \Phi$

where $A^{I}$ is the azimuth of the CCD-sensor in camera direction I, $\beta$ the angle between CCD-sensor and tilt sensor and $\Phi$ the astronomical latitude.

As the astronomical coordinates $(\Phi, \Lambda)$ of the camera refer to the current Earth rotation pole, which changes its position with time, a reduction to the fixed IERS reference pole is carried out. The equation of polar motion correction reads as (cf. Torge 2001):

$\delta \Phi_{\mathrm{P}}=-\left(x_{\mathrm{P}} \cos \Lambda-y_{\mathrm{P}} \sin \Lambda\right)$,

$\delta \Lambda_{\mathrm{P}}=-\left(x_{\mathrm{p}} \sin \Lambda+y_{\mathrm{P}} \cos \Lambda\right) \tan \Phi$

with $\left(x_{\mathrm{p}}, y_{\mathrm{p}}\right)$ coordinates of the terrestrial pole as referred to the IERS reference pole. Adding the tilt correction (Eq. 15) and polar motion correction (Eq. 16) to the coordinates of the camera axis $(\Phi, \Lambda)_{\mathrm{R}}$ (Eq. 11) yields the definite direction of the plumb line $(\Phi, \Lambda)$ :

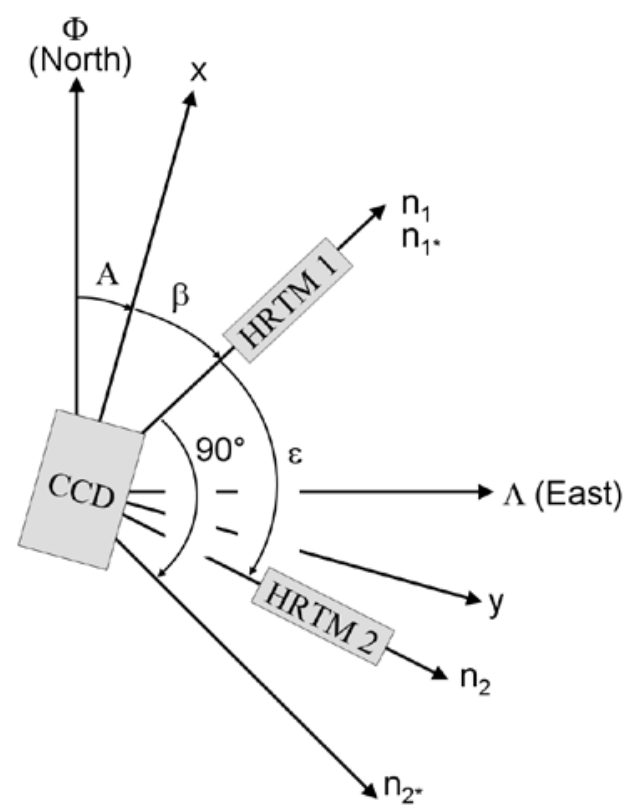

Figure 9: Coordinate systems used for calibration. $(\Phi, \Lambda)$ astronomical coordinate system, $(x, y)$ image coordinate system as realized by the CCD, $\left(n_{1}, n_{2}\right)$ sheared coordinate system of the tilt sensors HRTM1 and HRTM 2, $\left(n_{\left.1^{*}, n_{2 *}\right)}\right.$ orthogonal coordinate system for the tilt corrections. A = astronomical azimuth of CCD, $\beta$ = rotation angle between tilt coordinate system and CCD, $\varepsilon=$ shearing of the tilt sensors.

$$
\begin{aligned}
& \Phi=\Phi_{\mathrm{R}}+\delta \Phi_{\mathrm{n}}+\delta \Phi_{\mathrm{p}} \\
& \Lambda=\Lambda_{\mathrm{R}}+\delta \Lambda_{\mathrm{n}}+\delta \Lambda_{\mathrm{p}}
\end{aligned}
$$

Finally, vertical deflections $(\xi, \eta)$ are obtained taking the geodetic position $(\varphi, \lambda)$ of the camera into account (Eq. 2). 


\section{Calibration}

Systematic error sources of the DZCS are reduced not only by suitable measuring strategies (measurement in two directions I-II and time-symmetric sequence I-II-II-I) but also by tailored calibration procedures which are routinely performed. Thorough calibration is required for the motion function of the shutter and for the tilt sensors.

\section{Calibration of the shutter}

Errors in the determination of the exposure epoch propagate directly into astronomical longitude $\Lambda$. Therefore, the precise knowledge of the motion characteristics of the shutter is necessary ("personal equation of the shutter"). A laboratory calibration procedure was developed which is based on the comparison of two electric signals using an oscilloscope (cf. Hirt 2004, Somieski 2008). The first signal is the shutter opening pulse from the CCD control unit that is synchronously sent to the shutter and to the GPS-receiver that measures the epoch on GPS-time scale. The second signal is generated by a laser beam and a light-sensitive diode aligned either to the edges or the center of the CCD. The different reflexion characteristics of the shutter blades (their dark surface cause diffuse reflexion) and the CCD (strong reflected signal) give information on the true behavior of the shutter motion. The comparison of both signals revealed a significant delay of the shutter motion which is a function of temperature as well as a slight asymmetry between shutter opening and closing. Therefore, the GPS-epochs are corrected for the shutter motion characteristics using a calibration function. The accuracy of the implemented timing technique has been found to be about $1 \mathrm{~ms}$. This corresponds to 0.015 ” error in astronomical longitude which is completely sufficient for most DZCS applications.

\section{Calibration of the tilt sensors}

The method of celestial calibration (Hirt 2004) allows the determination of the functional relation between the tilt sensors and the CCD-sensor. The method provides leastsquares estimates of the scale factors $m_{1}, m_{2}$ of the tilt sensors and of the orientation angle $\beta$ between the CCD-sensor with respect to the coordinate system of the tilt sensors. Moreover, the model accounts for the shearing angle $\varepsilon$ between the measuring axes of the two tilt sensors. The geometric relations between the astronomical coordinate system, the CCD and tilt sensors are illustrated in Fig. 9.

The celestial calibration utilizes the fact that an inclination of the camera (with respect to the plumb line) linearly changes the astronomical coordinates of the camera axis as well as the readings of the tilt sensors. For calibration, the zenith camera is systematically misaligned in different directions (e.g. 100" northwards, 100" westwards, etc.). The comparison of angular differences as observed with the tilt sensors and ICRS stars (giving the astronomical coordinates) allows to estimate the scale factors $m_{1}, m_{2}$ of the two tilt sensors as well as the rotation angle $\beta$ and shearing parameter $\varepsilon$. The main benefit of the method of celestial calibration is that the scale factors of the tilt sensors are provided consistently with the ICRS angular scale on a relative accuracy level of $0.1-0.2 \%$. Hence, the related inaccuracies of tilt values (due to the uncertainty of the scales) are below 0.01 ” in most cases (assuming tilt values of about $\left.5^{\prime \prime}\right)$. The rotation $\beta$ and shearing $\varepsilon$ are estimated accurate to about $0.03^{\circ}$, allowing a precise tilt correction.

\section{Accuracy}

The astrogeodetic determination of vertical deflections is characterized as absolute observation technique. Contrary to differential geodetic methods (e.g. DGPS) systematic errors (e.g. instrumental drifts or improperly modeled effects in the observation data) are not canceled out. Therefore particular attention was laid on the adequate consideration of all systematic instrumental errors. Repeatedly performed observations in different nights (under changing atmospheric conditions) and comparative measurements with different types of data are necessary in order to obtain reasonable accuracy estimates and to monitor the instrumental stability.

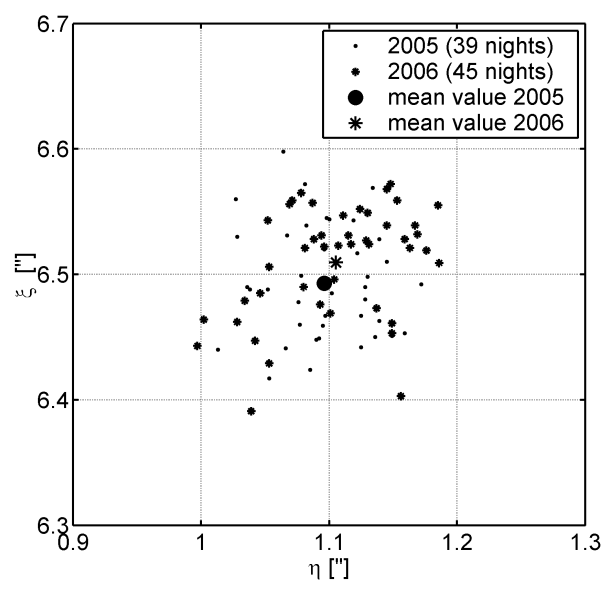

Figure 10: Results of repeated $(\xi, \eta)$ vertical deflection measurements at Hanover station from 2005 to 2006. The figure shows the nightly mean values acquired over 84 nights.

In order to study accuracy, atmospheric influences and instrumental stability, a comprehensive series of vertical deflection observations using the system TZK2-D has been acquired at a dedicated station located near the IfE in Hannover. Since 2003, vertical deflections were observed within 107 different nights over a period of 3.5 years. The data collected at Hannover station is the largest DZCS observation series available to date. The series covers a wide spectrum of environmental conditions (e.g. season, temperature, air pressure) and resulting anomalous refraction (see below). Therefore, it is believed that the analysis of single and mean values computed from this data set provides well-founded empirical accuracy estimates. A comprehensive study on the accuracy of DZCS observations evaluating these data has already been published (Hirt and Seeber 2008). In the following, some important results are summarized based on the analysis of vertical deflection data sets collected since 2005 . The earlier data sets (23 nights in 2003-2004) are omitted because they were affected by the azimuth dependent error, an additional contributor of instrumental noise that was completely mitigated since 2005. For a more detailed discussion of noise sources of zenith camera observations the reader is referred to Hirt and Seeber (2008). 


\begin{tabular}{|r|r|r|r|r|}
\hline $\begin{array}{r}\text { Observation } \\
\text { class }\end{array}$ & $\begin{array}{r}\text { Observation } \\
\text { duration }\end{array}$ & $\begin{array}{r}\text { Single ob- } \\
\text { servations }\end{array}$ & Processed stars & $\begin{array}{r}\text { Level of } \\
\text { accuracy [“] }\end{array}$ \\
\hline $\begin{array}{r}\text { Single } \\
\text { observation }\end{array}$ & $25-30 \mathrm{sec}$ & 1 & $40-100$ & 0.2 \\
\hline Field observation & $20-25 \mathrm{~min}$ & $40-50$ & $2000-5000$ & 0.08 \\
\hline $\begin{array}{r}\text { Extended } \\
\text { observation }\end{array}$ & $>50-60 \mathrm{~min}$ & $>100$ & $>10000-20000$ & 0.05 \\
\hline
\end{tabular}

Table 2: Accuracy of vertical deflection measurements using DZCS

From 2005 to 2006, about 23,600 $(\xi, \eta)$ single values have been collected at Hannover station over 84 nights. Over most nights, at least 100-200 single observations are available. The overall standard deviation of these single observations has been found to be about 0.22”. A reduction of observational noise (mainly due to image coordinate measurement and short-period refraction effects called scintillation) is easily achievable by forming mean values. In a first step, $(\xi, \eta)$ average values were computed from each set of 50 single observations of the data series (this corresponds to a field observation). The standard deviation computed from these data is about 0.06-0.07”. Hence, modern DZCS field observations show an excellent repeatability, even under changing atmospheric conditions. In a second step, $84(\xi, \eta)$ nightly mean values (extended observations) were formed by averaging all single observations available over the different nights (Fig. 10). It has been found that the $(\xi, \eta)$ extended observations are accurate to 0.045 ”. A detailed analysis revealed that the average of about 100 single solutions yields a standard deviation of about 0.05 " and that additional observations do not further enhance the attainable accuracy. The analysis showed on the one hand that for the first time the 0.05 " accuracy level was accessed with a transportable astrogeodetic field instrumentation. On the other hand, it was found that anomalous refraction is likely the prevailing error source that limits a further enhancement of accuracy.

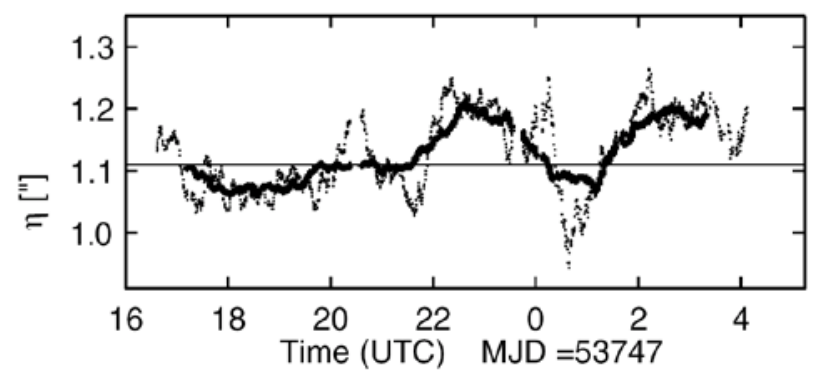

Figure 11: Time series of the Vertical deflection component $\eta$ at Hanover station. Observation span was $11 \mathrm{~h}$. Dotted line: 20 min average, thick line: $2 \mathrm{~h}$ average. Horizontal line: yearly mean value as a reference.

Anomalous refraction is a systematic refraction effect in zenith due to horizontal temperature gradients occurring e.g. at land-sea transitions, in strongly sloped terrain, due to air mass convection, or during passing weather fronts (e.g.
Sugawa 1956, Bretterbauer 1965, Ramsayer 1967). An impression on the behavior of anomalous refraction is given in Fig. 11, showing a vertical deflection time series acquired at Hannover station. The data, which is smoothed using a moving average filter with window widths of $20 \mathrm{~min}$ and $2 \mathrm{~h}$, contains correlated wave-like structures with amplitudes between 0.05 " and 0.20 " at time scales of some hours. These effects most probably originate from the fluctuations of anomalous refraction in zenith (Hirt 2006).

At a number of field stations, the Hannover DCZS TZK2-D was used repeatedly in different nights for the determination of vertical deflections. The residuals between each pair of vertical deflection values allowed the computation of standard deviations for the $(\xi, \eta)$ data. In the Bavarian Alps, 38 stations have been observed, each in two different nights (50 single observations and 20 min observation time per station each evening), yielding standard deviations from double observations for $(\xi, \eta)$ of about 0.08 " (cf. Hirt and Flury 2008). A similar experiment carried out at 39 stations in the Harz mountains (Lower Saxony) showed standard deviations of 0.08 "-0.09" (Hirt et al. 2008). These figures clearly reveal that DZCS allow the determination of vertical deflection data with accuracies better than 0.1”.

In order to detect systematic errors possibly contained in the data, vertical deflection measurements have been synchronously performed with the camera systems DIADEM and TZK2-D and, additionally, at selected stations with different types of comparative data available. Parallel observations using both cameras have been carried out at different sites in Switzerland 2003 and 2005. The correspondence of the data sets acquired is on the order of 0.1” and better (cf. Müller et al. 2004, Somieski 2008). At the site of the former Hamburg Photographic Zenith Tube (PZT), an instrument deployed for determining Earth orientation in the past, the TZK2-D was used from 20032004 for comparison with the high-precision PZTobservations. The agreement of both data sets is within 0.1 ”. Moreover, comparisons were made with vertical deflections computed from gravimetric geoid models, showing insignificant differences of about 0.1" (Hirt et al. 2004). In 2005, comparison measurements were carried out at some stations in the Netherlands. There, vertical deflections were determined with high-precision by visually performed observations (Schreutelkamp 2000). The agreement between the DZCS observations and the visual observations was found to be on the order of some 0.01". Concluding, in no case significant systemic errors were detected by the comparison measurements. 
As a general conclusion, the analysis of repeated and comparative measurements has demonstrated the considerable accuracy of vertical deflection data determined with DZCS. The noise level for single observations is about 0.2 ", the accuracy for mean values formed by 50 single observations has been found to be about 0.08 ", and the one of 100 observations is on the order of 0.05 " (Tab. 2). If compared to the accuracy of formerly used analogue zenith cameras (order of 0.5”, cf. Seeber and Torge 1985, Wissel 1982, Bürki 1989), the accuracy of DZCS is considerably enhanced by about one order of magnitude. Besides the new star catalogues and high-precision imaging and tilt sensors, the redundancy of observation - several 1000 stars are measured at each station - is certainly responsible for achieving the unprecedented 0.05-0.1” accuracy level. Moreover, it is remarkable that homogeneous accuracy values are obtained for both vertical deflection components which is related to the precise timing procedure using GPS.

\section{Applications}

Owing to the considerable advancements in geodetic astronomy made with the development of DZCS, vertical deflection measurements have been increasingly performed over the past years. The main area of application is the local and regional determination of the shape of Earth gravity field, getting more and more important since geoid and quasigeoid models play a decisive connecting role between ellipsoidal heights as observed with GPS and normal or orthometric heights with physical meaning (cf. Torge 2001). Astrogeodetic vertical deflections contribute to a considerable reinforcement in the gravimetric determination of the geoid and its fine structures, particularly in mountainous areas (e.g. Marti 1997, 2004) and may serve as independent check on gravimetric geoid modeling as well as on GPS/leveling data. Therefore, the Hannover and Zurich DZCS have been deployed in several dedicated projects in Europe. In 2003, a joint campaign took place in Switzerland where 68 new stations were observed using both DZCS (Müller et al. 2004, Somieski 2008). Further stations were observed with the Zurich camera DIADEM in Portugal 2004 and Greece 2006 (Müller et al. 2006, Somieski et al. 2007). The deflection observations performed in Greece were already used for the computation of a regional geoid model and, in addition, for a geophysical interpretation of density anomalies (Somieski 2008).

In local geodetic precision networks vertical deflections are often required for the reduction of terrestrial observations as well as for a precise connection between GPS heighting and spirit leveling. This holds especially true in mountainous regions. An example of the use of DZCS is the AlpTransit project in Switzerland, a high-precision geodetic network for a railway tunnel of $57 \mathrm{~km}$ length crossing the Swiss Alps, cf. Bürki et al. (2005, 2007a), Somieski (2008).

The classical technique of astronomical leveling was successfully applied with the Hannover DZCS for the highlyaccurate determination of geoid- and quasigeoid information along profiles. Because of the efficiency of the DZCS observation, 10 to 20 stations could be observed over clear nights, thus allowing to collect dense deflection data sets in reasonable measuring periods. At very densely-distributed stations in a test area near Hannover, vertical deflection measurements were carried out with an unprecedented spacing of $50 \mathrm{~m}$ (profile length of $7 \mathrm{~km}, 140$ stations). The data set was used for the analysis of the fine structure of gravity field. It was demonstrated that astrogeodetic gravity field surveys may be performed at the sub-millimeter level (order of a few $0.1 \mathrm{~mm}$ over some $\mathrm{km}$ ), cf. Hirt and Seeber (2006), Hirt (2009). Hence, the astronomical method using DZCS observations can meet extraordinary high accuracy requirements, e.g. associated with the alignment of new linear accelerators (Schlösser and Herty 2002, Becker et al. 2002, ILC 2007).

In the Bavarian Alps, vertical deflections were collected with the Hannover DZCS along a $23 \mathrm{~km}$ traverse in a dense arrangement (about 100 stations and $230 \mathrm{~m}$ spacing) and used for the validation of gravimetric quasigeoid models (Hirt et al. 2007). A similar validation experiment was carried out in the Harz mountains (Northern Germany) where deflections were observed at about 115 stations along a profile of $65 \mathrm{~km}$ length (600 m spacing). Both projects showed that vertical deflections provide information on the geometry of the gravity field accurate to about $0.5-1 \mathrm{~mm}$ over 10 km (cf. Hirt and Flury 2008, Hirt et al. 2008). Over distances of several $100 \mathrm{~km}$, astronomical leveling with the Hannover DZCS was applied on the cm-level (Voigt et al. 2007).

\section{Conclusions}

This paper has described the recent progress made with the determination of vertical deflections using high-precision digital zenith camera systems. Two state-of-the-art DZCS have been successfully constructed in Zurich and Hannover. The use of CCD-technology for star imaging enables a very efficient observation and processing of star image data. A second important contributor to the advancements are the highly-accurate and dense star catalogues Tycho-2 and UCAC providing the celestial reference data for the data reduction.

In comparison with modern satellite positioning, the new astrogeodetic observation systems have achieved a similar degree of automation, ease and real-time capability as such complying with today's geodetic standards. Due to the automation in observation and processing, including leveling, exposure, data acquisition, transfer and data reduction, the determination of vertical deflections using the measuring systems DIADEM and TZK2-D requires just "one mouse click".

During 20 min observation time, about 50 single observations are usually carried out at field stations, yielding an accuracy of about 0.08 " for the mean values. It was further shown that the even 0.05 " accuracy level is attainable after about $1 \mathrm{~h}$ observation time. Because of the significantly increased accuracy and efficiency of DZCS for vertical deflection measurements, astrogeodetic techniques have been reactivated for precise local and regional geoid determinations. DZCS vertical deflection data were successfully used as reinforcement of gravimetric geoid solutions as well as for the highly-accurate determination of the geometry of the gravity field along profiles for validation purposes. 


\section{Acknowledgement}

The development and application of the Hannover DZCS TZK2-D is supported by German National Research Foundation (Deutsche Forschungsgemeinschaft) within the research projects Se 313/21 (2001-2004) and Se 313/22 (2004-2006). The development and application of the Swiss system DIADEM was supported by ETH Zurich. The authors thank the two anonymous reviewers and the Editor for their valuable comments on the manuscript.

\section{Bibliography}

Bangert, J.A. and Kaplan, G.H. (1998). "NOVAS-C Naval Observatory Vector Astrometry Subroutines C Language Version 2.0.” United States Naval Observatory, Washington, DC.

Becker, F., Coosemans, W., and Jones, M. (2002). "Consequences of Perturbations of the Gravity Field on HLS Measurements." Proc. of 7th Int. Workshop on Accelerator Alignment (IWAA), SPring-8, Japan, 327-342.

Birardi, G. (1976). "The establishment of a net of vertical deflection points in Italy by means of a photoastronomic procedure.” Instituto Geografico Militare. Paper presented to the XVI IUGG General Assembly, Grenoble 1975.In: Bolletino di Geodesia e Scienze Affini 2, Firenze.

Bretterbauer, K. (1965). "Über mögliche Refraktionsanomalien infolge von Schichtenneigungen”. Österreichische Zeitschrift für Vermessungswesen 53(4), 113-119.

Bretterbauer, K. (1997). "Eine Renaissance der Astrometrie in der Geodäsie”. Österreichische Zeitschrift für Vermessung und Geoinformation 85(1), 15-20.

Bürki, B. (1989). "Integrale Schwerefeldbestimmung in der Ivrea-Zone und deren geophysikalische Interpretation“. Geodätischgeophysikalische Arbeiten in der Schweiz, Nr. 40, Schweizerische Geodätische Kommission.

Bürki, B., Müller, A., and Kahle, H.-G. (2004). DIADEM: "The New Digital Astronomical Deflection Measuring System for Highprecision Measurements of Deflections of the Vertical at ETH Zurich.” Electronic Proc. IAG GGSM2004 Meeting in Porto Portugal. Published also in: CHGeoid 2003, Report 03-33 A (ed. U. Marti et al.), Bundesamt für Landestopographie (swisstopo), Wabern, Schweiz.

Bürki, B., Ganz, M., Hirt, C., Marti, U., Müller, A., Radogna, P.V., Schlatter, A., and Wiget, A. (2005). "Astrogeodätische und gravimetrische Zusatzmessungen für den GotthardBasistunnel”. Report 05-34, Bundesamt für Landestopographie (swisstopo), Wabern, Schweiz.

Bürki, B., Somieski, A.E., Hirt, C., Marti, U., P.V. Radogna and A Wiget (2007a). "Geodetic Works for AlpTransit Gotthard (Deflections of the Vertical, Azimuths and Gravity Measurements).” In: Swiss National Report on the Geodetic Activities in the years 2003-2007, presented to the XXIV General Assembly of the IUGG in Perugia, Italy, ISBN 978-3908440-15-4, Swiss Geodetic Commission, 108-109.

Bürki, B., Somieski, A.E., Sorber, P., H.-G. Kahle and Hirt, C. (2007b). "The Digital Astronomical Deflection Measuring System (DIADEM)." In: Swiss National Report on the Geodetic Activities in the years 2003-2007, presented to the XXIV General Assembly of the IUGG in Perugia, Italy, ISBN 978-3908440-15-4, Swiss Geodetic Commission, 143-144.

Buil, C. (1991). "CCD Astronomy. Construction and Use of an Astronomical CCD Camera.” Willmann-Bell, Richmond, Virginia.

Chesi, G. (1984). "Entwicklung einer tragbaren Zenitkammer und ihr Einsatz im 47. Parallel.” Deutsche Geodätische Kommission C 287.

Eissfeller, B. and Hein, G.W. (1994). “Astrogeodetic Levelling with an Integrated DGPS/CCD Star Camera System.” Proc. International Symposium on Kinematic Systems in Geodesy, Geomatics and Navigation KIS 94, Banff, Canada, 431-442.

ESA (1997). “The Hipparcos and Tycho Catalogues.” ESA SP-1200, European Space Agency.

Featherstone, W. (1997). “ The Importance of Including the Geoid in Terrestrial Survey Data Reduction to the Geocentric Datum of Australia.” The Australian Surveyor 42(1), 45-50.
Fosu, C. (1999). "Astrogeodetic Levelling by the Combination of GPS and CCD Zenith Camera." Schriftenreihe Studiengang Vermessungswesen Universität der Bundeswehr München, Heft 63.

Guillaume, S. and Bürki, B. (2008). "Digital Astrogeodetic Online Observation System Daedalus. User Manual V1.0“. Report Institut für Geodäsie und Photogrammetrie, ETH Zürich.

Gessler, J. (1975). "Entwicklung und Erprobung einer transportablen Zenitkamera für astronomisch-geodätische Ortsbestimmungen.” Wiss. Arb. Lehrst. für Geod., Phot. und Kart. Techn. Univ. Hannover Nr. 60.

Grafarend, E.W. and Awange, J.L. (2000). "Determination of Vertical Deflections by GPS /LPS measurements”. Zeitschrift für Vermessungswesen 125(8), 279-288.

Groth, E.J. (1986). "A Pattern Matching Algorithm For TwoDimensional Coordinate Lists.” Astron. J., 91, 1244-1248.

Haralick, R.M. and Shapiro, L.G. (1992/1993). "Computer and Robot Vision Vol 1./2.” Addison Wesley, Reading, Massachusetts.

Helmert, F. (1913). "Die Bestimmung des Geoids im Gebiet des Harzes." Sitzungsberichte der Königlichen Preußischen Akademie der Wissenschaften zu Berlin, 1. Hb, 550-560.

Heiskanen, W.A. and Moritz, H. (1967). "Physical Geodesy.” Freeman, San Francisco.

Hirt, C. (2001). “Automatic Determination of Vertical Deflections in Real-Time by Combining GPS and Digital Zenith Camera for Solving the GPS-Height-Problem." Proc., 14th International Technical Meeting of The Satellite Division of the Institute of Navigation, Alexandria, 2540-2551.

Hirt, C. (2004). "Entwicklung und Erprobung eines digitalen Zenitkamerasystems für die hochpräzise Lotabweichungsbestimmung.“, Ph.D. Thesis. Wissen. Arb. der Fachrichtung Geodäsie und Geoinformatik an der Universität Hannover Nr. 253.

URL: http://edok01.tib.unihannover.de/edoks/e01dh04/393223965.pdf.

Hirt, C. (2006). "Monitoring and analysis of anomalous refraction using a digital zenith camera system."

Astron. Astrophys. 459, 283-290. DOI 10.1051/00046361:20065485.

Hirt, C. (2008). "Zur Berücksichtigung von Scherung und Umschlagwinkel bei der Neigungsmessung mit zweiachsigen Neigungssensoren. “ Zeitschrift für Vermessungswesen 133(4), 266-273.

Hirt, C. (2009). "Hochauflösende astrogeodätische Bestimmung von Geoid- und Äquipotentialprofilen mit Submillimetergenauigkeit für die Vermessung von Teilchenbeschleunigern.“ Allgemeine Vermessungsnachrichten 2009(2), 48-63.

Hirt, C. and Bürki, B. (2002). "The Digital Zenith Camera - A New High-Precision and Economic Astrogeodetic Observation System for Real-Time Measurement of Deflections of the Vertical." Proc., 3rd Meeting of the International Gravity and Geoid Commission of the IAG, Thessaloniki (ed. I. Tziavos), 161-166.

Hirt, C. and Kahlmann, T. (2004). "Hochpräzise Neigungsmessung mit dem elektronischen Pendelneigungssensor HRTM.“ Zeitschrift für Vermessungswesen 129(4), 266-276.

Hirt, C., Reese, B., and Enslin, H. (2004). "On the Accuracy of Vertical Deflection Measurements Using the High-Precision Digital Zenith Camera System TZK2-D.” Proceed. GGSM 2004 IAG International Symposium Porto, Portugal (ed. C. Jekeli et al.), Springer, Heidelberg, 197-201.

Hirt, C., Wallace, P. and Schreutelkamp. F. (2005). "Comparison of Topocentric Places and Time Computations.” Report, Institut für Erdmessung, University of Hannover.

Hirt, C. and Seeber, G. (2006). "High-Resolution Local Gravity Field Determination at the Sub- Millimeter Level using a Digital Zenith Camera System.” In: Proc., Dynamic Planet, Cairns 2005 (ed. P. Tregoning und C. Rizos), IAG Symposia 130, 316-321.

Hirt, C., Denker, H., Flury, J., Lindau, A. and Seeber, G. (2007) "Astrogeodetic Validation of Gravimetric Quasigeoid Models in the German Alps - First Results.” Proceed. 1. Intern. Symp. of the International Gravity Field Service, Istanbul, Turkey, Harita Dergisi, Special Issue 18, 84-89.

Hirt, C., Feldmann-Westendorff, U., Denker, H., Flury, J., Jahn, C.-H., Lindau, A, Seeber, G. and Voigt, C. (2008). "Hochpräzise Bestimmung eines astrogeodätischen Quasigeoidprofils im Harz 
für die Validierung des Quasigeoidmodells GCG05.” Zeitschrift für Vermessungswesen 133(2), 108-119,

Hirt and Flury (2008). "Astronomical-topographic levelling using highprecision astrogeodetic vertical deflections and digital terrain model data." J. Geodesy, 82(4-5), 231-248.

Hirt and Seeber (2008). "Accuracy analysis of vertical deflection data observed with the Hannover Digital Zenith Camera System TZK2-D.” J. Geodesy, 82(6), 347-356.

Høg, E., Fabricius, C., Makarov, V. V., Urban, S., Corbin, T., Wycoff, G., Bastian, U., Schwekendiek, P. and Wicenec, A. (2000) "The Tycho-2 Catalogue of the 2.5 Million Brightest Stars." Astron. Astrophys. 355, L27-L30.

Howell, S.B. (2000). Handbook of CCD-Astronomy. Cambridge University Press.

ILC (2007). "International Linear Colider. Reference Design Report." URL: media.linearcollider.org/rdr draft v1.pdf

Jekeli, C. (1999). "An analysis of vertical deflections derived from highdegree spherical harmonic models.” J. Geodesy, 73(1), 10-22.

Jekeli, C. (2006). "Geometric Reference Systems in Geodesy.” Lecture Notes. Division of Geodesy and Geospatial Science, School of Earth Science, Ohio State University. Ohio.

Kaplan, G. H., Hughes, J.A., Seidelmann, P.K., Smith, C.A. and Yallop, B.D. (1989). "Mean and Apparent Place Computations in the New IAU System. III Apparent, Topocentric, and Astrometric Places of Planets and Stars.” Astron. J. 97, 1197-1210.

Kudrys J. (2007). „Automatic determination of vertical deflection components from GPS and zenithal star observations." Acta Geodyn. Geomater., 4(4), 169-172.

Li, X. and Jekeli, C. (2008). "Ground-vehicle INS/GPS vector gravimetry.” Geophysics, 73(2), I1-I10. DOI: $10.1190 / 1.2821155$

Marti, U. (1997). „Geoid der Schweiz 1997.“ Geodätischgeophysikalische Arbeiten in der Schweiz Nr. 56. Schweizerische Geodätische Kommission.

Marti, U. (2004). "High-precision combined geoid determination in Switzerland." Proceed. GGSM 2004 IAG International Symposium Porto, Portugal (ed. C. Jekeli et al.), Springer, Heidelberg, 377-382.

Monet, D.G. and Dahn, C.C. (1983). "CCD Astrometry I. Preliminary Results from the KPNO 4-M/CCD Parallax Program.” Astron. J., 88, 1489-1507.

Müller, A., Bürki, B., Kahle, H.-G., Hirt, C., and Marti, U. (2004). “First Results from New High-precision Measurements of Deflections of the Vertical in Switzerland.” Proceed. GGSM 2004 IAG International Symposium, Porto, Portugal (ed. C. Jekeli et al.), Springer, Heidelberg, 143-148.

Müller, A., Bürki, B., Limpack, P., Kahle, H.-G., Grigoriadis, V.N., Vergos, G.S. and Tziavos, I.N. (2006). "Validation of marine geoid models in the North Agean Sea using satellite altimetry, marine GPS data and astrogeodetic measurements.” Proc. 1. Intern. Symp. of the International Gravity Field Service, Istanbul, Turkey, Harita Dergisi, Special Issue 18, 90-95.

Ramsayer, K. (1967). "Investigation on Errors in the Determination of Astronomical Refraction.” Österreichische Zeitschrift für Vermessungswesen, Sonderheft 25, 260-269.

Schildknecht, T. (1994). "Optical Astrometry of Fast Moving Objects Using CCD Detectors.” Geodätisch-geophysikalische Arbeiten in der Schweiz Nr. 49, Schweizerische Geodätische Kommission.

Schlösser, M. and Herty, A. (2002). "High Precision Survey and Alignement of Large Linear Colliders -Vertical Alignement." Proc. of 7th Int. Workshop on Accelerator Alignment (IWAA): 343-355, SPring-8, Japan.

Schödlbauer, A. (2000). "Geodätische Astronomie - Aussichten an der Schwelle zum 21. Jahrhundert.” Schriftenreihe Studiengang Geodäsie und Geoinformation der Universität der Bundeswehr München, Heft 60-1, 27-56.

Seeber, G. (1972). "Über das stochastische Verhalten von photographisch bestimmten Stern- und Satellitenkoordinaten." Deutsche Geodätische Kommission C 178, München.

Seeber, G. (2003). “Satellite Geodesy. Second Edition.” W. de Gruyter,

Berlin, New York.

Seeber, G. and Torge, W. (1985). „Zum Einsatz transportabler Zenitkameras für die Lotabweichungsbestimmung." Zeitschrift für Vermessungswesen 110, 439-450.

Seidelmann, P. (1992). "Explanatory Guide to the Astronomical Almanach.” University Science Books, Mill Valley, CA.
Soler T., Carlson A. E. and Evans A. G. (1989). "Determination of Vertical Deflections using the Global Positioning System and Geodetic Leveling.” Geophys. Res. Lett., 16(7), 695-698.

Somieski, A.E., Bürki, B., Kahle, H.-G., Marti, U., Hirt, C. and Tziavos, I. N. (2007). "Determination of Highly-Precise Deflections of the Vertical: Switzerland 2003/2005, Portugal 2004 and Greece 2005.” In: Swiss National Report on the Geodetic Activities in the years 2003-2007, presented to the XXIV General Assembly of the IUGG in Perugia, Italy, ISBN 978-3-908440-15-4, Swiss Geodetic Commission, 47-52.

Somieski, A.E. (2008). "Astrogeodetic Geoid and Isostatic Considerations in the North Aegean Sea, Greece.”, Diss. ETH No. 17790, ETH Zurich, Switzerland.

Stone, R.C. (1988). "A Comparison of Digital Centering Algorithms." Astron. J., 97, 1227-1237.

Schreutelkamp, F. H. (2000). "Schietloodafwijkingen bepaald uit geodetisch-astronomische waarnemingen - Nederland dertig meter dichter bij Greenwich.” Geodesia 4 (2000), 155-162.

Sugawa, C. (1956). "On the Relation of the Anomalous Refraction on the Latitude Observations.” Publ. Astron. Soc. Japan., 8(1), $27-$ 39.

Torge, W. (2001). “Geodesy, Third Edition.” W. de Gruyter, Berlin, New York.

Tse C. M. and Baki Iz, H. (2006). "Deflection of the Vertical Components from GPS and Precise Leveling Measurements in Hong Kong.” J. Surv. Eng., 132(3), 97-100.

Valdes, F.G., Campusano, L.E., Velasques, J.D. and Stetson, P.B. (1995). "FOCAS Automatic Catalog Matching Algorithms." Proc., Astron. Soc. Pacific 107, 1119-1128.

Voigt, C., Denker, H. and Hirt, C. (2007). "Regional Astrogeodetic Validation of GPS/Levelling Data and Quasigeoid Models." Proc., IUGG General Assembly, Perugia 2007, IAG Symposia 133 (ed. M. Sideris), 413-420.

Wallace, P. (1994). "The SLALIB Library. Proc ADASS III.” Proc., Astron. Soc. Pacific Conference Series 61, 481-484.

Winter, L. (1999). "Wide-Field-Astrometrie mit CCD-Detektoren am Hamburger Zonenastrographen.“ PhD Thesis, Fachbereich Physik der Universität Hamburg, Hamburg.

Wissel, H. (1982). “Zur Leistungsfähigkeit von transportablen Zenitkameras bei der Lotabweichungsbestimmung.“ Wissen. Arb. Fach. Vermessungswesen Univ. Hannover Nr. 107.

Wolf, H. (1981). Der Lotabweichungsbegriff in der Geodäsie. In: Festkolloquium Karl Ramsayer, Deutsche Geodätische Kommission E 19, 16-32.

Zacharias, N., Zacharias, M. I., Urban, S. E., and Høg, E. (2000). "Comparing Tycho-2 astrometry with UCAC1." Astron. J., 120(2), 1148-1152.

Zacharias, N., Urban, S. E., Zacharias, M. I., Wycoff, G. L., Hall, D. M., Monet, D. G., and Rafferty, T. J. (2004). "The Second US Naval Observatory CCD Astrograph Catalog (UCAC2)." Astron. J., 127(5), 3043-3059. 